\title{
Motility-related actinin alpha-4 is associated with advanced and metastatic ovarian carcinoma
}

\author{
Maria V Barbolina ${ }^{1}$, Brian P Adley ${ }^{2}$, David L Kelly ${ }^{3}$, Angela J Fought ${ }^{4}$, Denise M Scholtens ${ }^{4}$, Lonnie D Shea ${ }^{1}$ \\ and M Sharon Stack ${ }^{5}$
}

Advanced and metastatic ovarian cancer is a leading cause of death from gynecologic malignancies. A more detailed understanding of the factors controlling invasion and metastasis may lead to novel anti-metastatic therapies. To model cellular interactions that occur during intraperitoneal metastasis, comparative cDNA microarray analysis and confirmatory real-time reverse transcription PCR (RT-PCR) were employed to uncover changes in gene expression that may occur in late stage ovarian cancer in response to microenvironmental cues, particularly native three-dimensional collagen I. Gene expression in human ovarian carcinoma tissues was evaluated on the RNA and protein level using real-time RT-PCR and immunohistochemistry. Cell invasion and migration were evaluated in a collagen invasion assay and a scratch wound assay. Three-dimensional collagen I culture led to differential expression of several genes. The role of actinin alpha-4 (ACTN4), a cytoskeleton-associated protein implicated in the regulation of cell motility, was examined in detail. ACTN4 RNA and protein expression were associated with advanced and metastatic human ovarian carcinoma. This report demonstrates that a cytoskeletal-associated protein ACTN4 is upregulated by three-dimensional collagen culture conditions, leading to increased invasion and motility of ovarian cancer cells. Expression of ACTN4 in human ovarian tumors was found to be associated with advanced-stage disease and peritoneal metastases.

Laboratory Investigation (2008) 88, 602-614; doi:10.1038/labinvest.2008.25; published online 24 March 2008

KEYWORDS: actinin alpha-4; invasion; metastasis; microenvironment; motility; ovarian carcinoma

Ovarian cancer accounts for more than 20000 deaths each year in the United States and almost 190000 worldwide, mainly due to metastatic disease. ${ }^{1-5}$ Epithelial ovarian carcinoma (EOC) comprises the majority of ovarian malignancies. Primary EOC is thought to arise from the ovarian epithelium and metastasizes by intraperitoneal shedding of the malignant cells, followed by adhesion to the mesothelium, submesothelial anchoring and development of secondary lesions, or metastases. ${ }^{6}$ Current treatment strategies for ovarian carcinoma patients include chemotherapy and surgical removal of the tumor; however, this approach is successful predominantly for patients with early-stage disease. $^{3,7}$ Unfortunately, there are no reliable molecular markers of the early stages of the malignancy and symptoms of ovarian cancer are relatively obscure, making early diagnosis problematic. $^{8}$ Therefore, the disease is often misdiagnosed or untreated until late stages, whereupon the current treatment strategies are less efficacious.
Death from ovarian carcinoma is mainly due to metastases that can grow to disproportionately large sizes compared with the primary tumor. Ovarian cancer metastases predominantly spread in the peritoneal cavity; however, in very advanced rare cases, secondary lesions can, in addition, be found in more distant organs, such as the brain. ${ }^{9}$ Certainly, this pattern of metastatic spread suggests that the microenvironment of the peritoneal cavity promotes development and progression of metastatic ovarian carcinoma. Indeed, a prevalent component of the intraperitoneal microenvironment, the submesothelial extracellular matrix protein type I collagen, has been demonstrated to play a crucial role in ovarian cancer cell adhesion and invasion. ${ }^{10,11}$ It was previously shown that ovarian cancer cells that encounter three-dimensional collagen I gain an increased invasive potential through overexpression of the membrane-anchored collagenase designated as membrane type-1 matrix metalloproteinase (MT1-MMP). ${ }^{12-15}$ These data suggest that type I

\footnotetext{
${ }^{1}$ Department of Chemical and Biochemical Engineering, Northwestern University, Chicago, IL, USA; ${ }^{2}$ Department of Pathology, Northwestern University, Chicago, IL, USA; ${ }^{3}$ Eppley Institute for Research in Cancer and Allied Diseases, University of Nebraska Medical Center, Omaha, NE, USA; ${ }^{4}$ Department of Preventive Medicine, Northwestern University, Chicago, IL, USA and ${ }^{5}$ Department of Pathology and Anatomical Sciences, University of Missouri, Columbia, MO, USA

Correspondence: Dr M Sharon Stack, PhD, Department of Pathology and Anatomical Sciences, University of Missouri School of Medicine, One Hospital Drive, M214E Medical Sciences Building, Columbia, MO, 65212, USA. E-mail: stackm@health.missouri.edu

Received 20 November 2007; revised 21 January 2008; accepted 22 January 2008
} 
collagen may play an active role in attracting ovarian carcinoma cells and facilitating localized submesothelial migration of malignant cells into the sites of secondary lesion formation. Acquisition of a migratory phenotype toward the preferential sites of metastatic dissemination is an important feature gained by many tumor cells in the course of malignant progression. ${ }^{16}$ As the molecular mechanisms that control late-stage ovarian cancer progression to metastasis are largely unknown, there is no comprehensive understanding of the factors responsible for regulation of cellular motility, much less of the mechanisms arising in response to microenvironmental stimuli.

To model regulatory interactions that occur during intraperitoneal metastasis, in vitro models using three-dimensional collagen I gel cultures were used to mimic cell-matrix interactions that accompany metastasis. ${ }^{17}$ Control conditions utilized thin layer or two-dimensional collagen I, which provides an adhesive substratum for ovarian cancer cells, but not the $\beta 1$-integrin clustering necessary for robust downstream signaling. ${ }^{14}$ Comparative cDNA microarray analysis and confirmatory real-time reverse transcription PCR (RT-PCR) were then employed to uncover changes in gene expression that may occur in late-stage ovarian cancer in response to microenvironmental cues. This approach yielded several differentially expressed genes previously associated with tumor progression and metastasis in other cancer models. Among these, the motility regulatory protein actinin alpha-4 (ACTN4) was chosen for further investigation. Realtime RT-PCR and western blotting demonstrate that ACTN4 is upregulated by three-dimensional collagen culture conditions. Further, combining real-time PCR detection of ACTN4 in human ovarian carcinoma tissues and immunohistochemical analysis of paired primary ovarian tumors and peritoneal metastases shows a correlation between expression of ACTN4 and tumor progression and metastasis. Silencing of ACTN4 expression in ovarian carcinoma cells using siRNA confirmed a role for ACTN4 expression in ovarian cancer motility and invasion. Together, these data implicate ACTN4 as an ovarian carcinoma metastasis-associated cytoskeletal protein playing a significant role in migration and invasion.

\section{MATERIALS AND METHODS Materials}

The ovarian carcinoma cell line DOV13 was kindly provided by Dr R Bast, Jr (MD Anderson Cancer Center, Houston, TX) and maintained in complete media (Gibco Invitrogen, Carlsbad, CA, USA) supplemented with $10 \%$ fetal bovine serum (Gibco Invitrogen) at $37^{\circ} \mathrm{C}$ in $5 \% \mathrm{CO}_{2}$ as described previously. ${ }^{11}$ Rat tail type I collagen was obtained from $\mathrm{BD}$ Biosciences. Polyclonal antibodies against ACTN4, control and ACTN4 siRNA were obtained from Santa Cruz Biotechnology (Santa Cruz, CA, USA). Polyclonal anti-MT1MMP and monoclonal $\beta$-tubulin-specific antibodies and human collagen I were obtained from Sigma (St Louis, MO, USA). Texas Red conjugated Fab fragment of donkey anti-goat antibody and Alexa Fluor 488 phalloïdin were obtained from Rockland Immunochemicals (Gilbertsville, PA, USA) and Invitrogen Corporation (Temecula, CA, USA), respectively. TissueScan real-time ovarian cancer disease panels containing 48 tissues covering four disease stages and normal tissues were obtained from Origene (Rockville, MD, USA).

\section{Three-Dimensional Collagen I Cell Culture Model}

As intraperitoneal metastasis of ovarian cancer cells involves invasion of the type I collagen-rich submesothelial matrix to anchor secondary lesions, initial stages of metastasis were modeled in vitro by plating cells atop a three-dimensional collagen I gel (3DCI). Cells were cultured for $8 \mathrm{~h}$ and collected in the presence of collagenase as described previously. ${ }^{12}$ Control cells were plated on thin-layer collagen I (two-dimensional collagen I or 2DCI) prepared by coating tissue culture plates by passive adsorption with a dilute $(10 \mu \mathrm{g} / \mathrm{ml})$ solution of collagen I overnight at $37^{\circ} \mathrm{C}$ in $5 \% \mathrm{CO}_{2}$.

\section{cDNA Microarray}

Total RNA was extracted using TRI Reagent (Molecular Research Center) according to the previously published procedure. ${ }^{18,19}$ All DNA microarray gene expression studies used human oligonucleotide arrays custom printed by a dedicated core facility within the Eppley Institute for Research in Cancer and Allied Diseases (University of Nebraska Medical Center, Omaha, NE, USA) as described previously. ${ }^{18,19}$ Arrays were constructed from a set of 12140 sense oligonucleotide (60-mers) probes designed for each human target gene by Compugen Inc. (Rockville, MD, USA) and manufactured by Sigma-Genosys Inc. (The Woodlands, TX, USA). Individual arrays contain 12288 spot features, including 12107 different genes, 28 replications of GAPDH and negative controls. Array quality was evaluated both upon initial synthesis, as well as over time, by hybridizing with previously characterized stock RNA, and comparing current with previous gene expression profiles using array median centering and correlation coefficients mapping programmed in MATLAB (The Mathworks Inc., Natick, MA, USA). In brief, approximately $40 \mu \mathrm{g}$ of experimental and reference RNA samples were reverse-transcribed with anchored oligo$\mathrm{dT}$ primer. cDNA was labeled with either Cy3 or Cy5 monofunctional NHS-ester (Amersham Pharmacia). Labeled cDNA in hybridization solution was applied to DNA microarrays and incubated at $42^{\circ} \mathrm{C}$ for $16-20 \mathrm{~h}$. After hybridization, microarray slides were washed, dried and scanned immediately with a ScanArray 4000 confocal laser system (Perkin-Elmer). Fluorescent intensities were backgroundsubtracted, and normalization and filtering of the data were performed using the QuantArray software package (Perkin-Elmer). After normalization, expression ratios were calculated for each feature. 


\section{Statistical Analysis of Microarray Data}

Analysis of microarray gene expression data, accumulated from three independent experiments, was performed using the limma package, ${ }^{20}$ available through the Bioconductor project $^{21}$ for use with $\mathrm{R}$ statistical software. ${ }^{22}$ Data quality was examined by looking for spatial effects across each microarray with image plots of raw $\log 2$ ratios and examining MA-plots of the M-values ( $\log 2$ ratios) vs A-values (average $\log 2$ intensities). Both views indicated no large-scale systematic effects indicative of technical problems with the arrays. Global loess within-array normalization after background subtraction was used to reduce systematic dye-related bias in the intensity values. ${ }^{23}$ After preprocessing, the analysis of differential gene expression was based on moderated $t$-statistics on the replicated $\log 2$ ratios for each gene. Statistical significance was assessed using an Empirical Bayes approach. ${ }^{20}$ Adjustment for multiple comparisons according to the false discovery rate method of Benjamini and Hochberg ${ }^{24}$ was performed, and genes with adjusted $P$-values less than 0.05 were selected as differentially expressed. Log 2 ratios were transformed back to fold change values for interpretation purposes in this report.

\section{mRNA Extraction and CDNA Synthesis for Real-Time RT-PCR}

To perform real-time RT-PCR, to confirm changes in gene expression identified by cDNA microarray, cells were cultured on 3DCI and 2DCI as described above. Total mRNA was purified from $1-2 \times 10^{6}$ cells using Aurum Total RNA Mini Kit (Bio-Rad) according to the manufacturer's instructions. cDNA was synthesized from $5-10 \mu \mathrm{g}$ of total RNA using iScript cDNA Synthesis Kit (Bio-Rad). mRNA purification and cDNA synthesis experiments were repeated three times.

\section{Quantitative Real-Time PCR}

Real-time PCR was carried out with the ABI Prizm (Applied Biosystems) according to the manufacturer's instructions. SYBR Green was used for quantitative PCR as a doublestranded DNA-specific fluorophore. The PCR was conducted by initial denaturation for $10 \mathrm{~min}$ at $95^{\circ} \mathrm{C}$ followed by 40 cycles of $94^{\circ} \mathrm{C}$ for $15 \mathrm{~s}$ and $60^{\circ} \mathrm{C}$ for $30 \mathrm{~s}$ using the iTaq SYBR Green Supermix (Bio-Rad). To determine the specificity of the PCR primers, melting curves were collected by heating the products at $95^{\circ} \mathrm{C}$, then cooling down to $65^{\circ} \mathrm{C}$, and then slowly melting at $0.5^{\circ} \mathrm{C} / \mathrm{s}$ up to $95^{\circ} \mathrm{C}$. Primers for mRNA detection of genes of interest were either constructed according to the requirements for oligonucleotide primers for real-time RT-PCR using Primer3 software or synthesized according to the previously published sequences as summarized in Table 1. Efficiency of amplification was determined using the standard curves method. Relative quantification of gene expression between experimental (3DCI) and control (2DCI) samples was measured by normalization against endogenous RPL-19 using the $\Delta \mathrm{C}_{\mathrm{T}}$ method. ${ }^{29}$ Before using RPL-19 as a control, it has been established that its expression correlated well with the total RNA concentration and did not change with the time and treatment used in our studies. Fold changes were quantified as $2^{-(\Delta \mathrm{Ct} \text { sample }-\Delta \mathrm{Ct} \text { control) }}$ as described previously. ${ }^{29}$

Real time RT-PCR was also used to detect the ACTN4 mRNA level in samples from tissues of normal ovary and ovarian carcinoma patients commercially available from Origene (TissueScan qPCR Ovarian Cancer I) according to the manufacturer's instructions (detailed description is available in Supplementary Table 1). Primers for ACTN4 and RPL-19 mRNA detection were those used for cDNA array validation experiments (Table 1), and primers for beta-actin detection (ACTNB) were supplied with the cDNA samples panel (Origene). $\mathrm{C}_{\mathrm{T}}$ values for ACTN4, RPL-19 and ACTNB were obtained using ABI Prizm (Applied Biosystems) according to the manufacturer's instructions as described above in Materials and methods.

\section{Immunohistochemistry}

Immunohistochemical analysis was done retrospectively on tumor tissue microarrays prepared with Institutional Review Board approval by the Pathology Core Facility of the Robert $\mathrm{H}$ Lurie Comprehensive Cancer Center at Northwestern University assembled from tissue originally taken for postoperative diagnostic purposes. The microarray tissue specimens included 17 paired primary and metastatic ovarian cancer tissues obtained during the same surgical procedure from patients who were not treated against ovarian cancer before the operation (15 serous, 2 endometroid). Samples were cut $3-4 \mu \mathrm{m}$ thick and deparaffinized. The cores were $1 \mathrm{~mm}$ in diameter. Antigen retrieval was accomplished by heat induction at $99^{\circ} \mathrm{C}$ for $\sim 45 \mathrm{~min}$. Immunohistochemical staining with antibodies to ACTN4 at 1:100 dilution was done according to standard procedures. Human testis tissue was used as positive controls for ACTN4. Analysis of tissue sections was done by light microscopy by an anatomic pathologist (B.P.A.) without previous knowledge of the clinical variables. Scoring of ACTN4 was assigned according to the average overall intensity of the staining and was graded as follows: $0=$ no staining, $1=$ fine granular staining, $2=$ somewhat coarse staining, but less than positive control tissue (human testis), $3=$ very coarse staining, similar to positive control tissue. Staining $<10 \%$ of tumor cells, regardless of intensity, was considered negative. Staining of $10-75 \%$ of tumor cells was considered focal positive, and staining greater than $75 \%$ of tumor cells was considered diffuse positive.

\section{Transient Transfections}

Transient transfections were performed using the lipofection method with Lipofectamine (Invitrogen) as a vehicle. ACTN4 and control siRNA (Santa Cruz Biotechnology) were transiently transfected into DOV13 cells according to the manufacturer's instructions. 
Table 1 Oligonucleotide primer sequences used in real time RT-PCR

\begin{tabular}{|c|c|c|}
\hline Gene & $\begin{array}{l}\text { Gene bank } \\
\text { accession no. }\end{array}$ & Sequence \\
\hline \multirow[t]{2}{*}{ FBXO10 } & AF176705 & Forward: 5'ACAACGTGCCCCTGTGT3' \\
\hline & & Reverse: 5'GGTGACCCTCAACAGTCA3' \\
\hline \multirow[t]{2}{*}{ ACTN4 } & NM_004924 & Forward: 5'CATATCAGGGGAGCGGTT3' \\
\hline & & Reverse: 5'GCAATAAAGTCCAGCGCT3' \\
\hline TXNIP & NM_06472 & Ref. 25 \\
\hline \multirow[t]{2}{*}{ TNFSF10 } & NM_003810 & Forward: 5'GGCATTCATTCCTGAGCAA3' \\
\hline & & Reverse: 5'GGACCATTTGTTGTCGTT3' \\
\hline CLDN1 & AF101051 & Ref. 26 \\
\hline \multirow[t]{2}{*}{ SLC20A1 } & NM_005415 & Forward: 5'CCAGTATCACACCGTGCA3' \\
\hline & & Reverse: 5'GGTाTGTCACCGGAGTCT3' \\
\hline \multirow[t]{2}{*}{ MXI1 } & NM_005962 & Forward: 5'ATTCCCGTCCATGCCGA3' \\
\hline & & Reverse: 5'GTAGATCTGTTGGCAGT3' \\
\hline \multirow[t]{2}{*}{$\mathrm{CHIC2}$} & NM_012110 & Forward: 5'CCGTATTTGGACTGAGCA3' \\
\hline & & Reverse: 5'CTCTGTTGATGCTGGCTT3' \\
\hline JUNB & NM_002229 & Ref. 27 \\
\hline \multirow[t]{2}{*}{ HHEX } & NM_002729 & Forward: 5'CTGATCAGGAAGTGGACA3' \\
\hline & & Reverse: 5'CTGAACATGCCAATGCCA3' \\
\hline \multirow[t]{2}{*}{ TGFB2 } & NM_003238 & Forward: 5'CTGCAGCACACTCGATAT3' \\
\hline & & Reverse: 5'GGCTCAGGATAGTCTTCT3' \\
\hline IL6 & M14584 & Ref. 28 \\
\hline
\end{tabular}

\section{Collagen Invasion}

Invasion assays were performed using Transwell chambers $(0.8 \mu \mathrm{m}$, Becton Dickinson, Bedford, MA, USA) as described previously. ${ }^{14}$ In brief, transwell inserts were coated on the bottom with a thin layer of human collagen (Sigma) as a chemoattractant for $1 \mathrm{~h}$ at $37^{\circ} \mathrm{C}$. The inner well of the filters contained $20 \mu \mathrm{g}$ of human collagen that was allowed to airdry overnight. Cells were grown until confluence and starved overnight in serum-free, insulin-free media to stop proliferation. Cells $(70000)$ were plated in the collagen-coated inserts and allowed to invade the collagen gel for $20 \mathrm{~h}$ at $37^{\circ} \mathrm{C}$ in serum-free conditions. Filters were collected and the cells adhering to the lower surface were fixed and stained using Diff-Quik staining kit (Dade Behring) according to the manufacturer's instructions. Cells in several random fields were counted and averaged. Invading cells were expressed as a percent of total cells added to the invasion chamber.

\section{Scratch Wound Assay}

DOV13 cells were cultured in standard conditions, as described above in the Materials and methods (Cell Culture), until $70-80 \%$ confluence following transient transfection with ACTN4 siRNA, control siRNA or phosphate-buffered saline as indicated in Materials and methods (Transient Transfections). Wounds were introduced into the confluent monolayers by a pipette tip. Wound closure was monitored over time and photographed using Zeiss Axiovert microscope at $5 \times$ magnification on the objective. The distance between the monolayers was measured using Zeiss Axiovert software in 10 random places, averaged and calculated into the percentage of the wound healing at a given time compared with the initial wound width.

\section{Western Blotting}

Cells incubated under various conditions were collected as described previously ${ }^{12}$ and lysed with buffer containing $50 \mathrm{mM}$ Tris, $150 \mathrm{mM} \mathrm{NaCl}, 1 \mathrm{mM} \mathrm{CaCl}, 1 \mathrm{mM} \mathrm{MgCl} 2,1 \%$ NP40, proteinase inhibitor cocktail (Roche). Cell lysates $(20 \mu \mathrm{g})$ were electrophoresed on 9\% SDS-polyacrilamide gels under reducing conditions, ${ }^{30}$ electroblotted to a polyvinylidene difluoride membrane, ${ }^{31}$ blocked with $5 \%$ skim milk in TBST ( $25 \mathrm{mmol} / \mathrm{l}$ Tris pH 7.5, $150 \mathrm{mmol} / \mathrm{l} \mathrm{NaCl}, 0.1 \%$ Tween 20$)$ for $1 \mathrm{~h}$ at room temperature $\left(20^{\circ} \mathrm{C}\right)$. Membranes were incubated for $1-2 \mathrm{~h}$ at room temperature with antibodies derived against proteins of interest. The antibodies were used at the following dilutions: 1:1000 for anti-human MT1-MMP polyclonal antibody in $3 \%$ bovine serum in TBST, 1:200 for goat-anti-ACTN4 in 5\% skim milk in TBST, $1: 1000$ for anti- $\beta$-tubulin monoclonal antibody in $5 \%$ skim milk in TBST. Immunoreactive bands were visualized with an anti-(rabbit-IgG)-peroxidase, anti(-goat-IgG)-peroxidase or anti-(mouse-IgG)-peroxidase (1:1000 in 5\% skim milk in TBST) and enhanced chemiluminescence using LAS3000 (Fujifilm) and LAS3000 ImageReader software. Band intensities were determined using LAS3000 ImageGauge software according to the manufacturer's instructions.

\section{Immunostaining}

Cells were cultured on glass slides or cover slips coated with thin-layer collagen I or covered with three-dimensional collagen I gels as described above. Then conditioned media were removed and cells were fixed onto the glass slide, followed by permeabilization for $1 \mathrm{~h}$ with $0.1 \%$ Triton X-100 in PBS containing 10\% goat serum. Permeabilized cells were incubated for $24 \mathrm{~h}$ at $4^{\circ} \mathrm{C}$ with anti-ACTN4 antibody in PBS containing $2 \%$ goat serum. 4'-6-Diamidino-2-phenylindole (DAPI) staining was used to visualize DNA. Alexa Fluor 488 phalloïdin staining was employed to visualize F-actin according to the manufacturer's instructions. Mouse antihuman ACTN4 antibody was used at a 1:50 dilution, and secondary donkey anti-goat-Texas Red antibody at 1:500 dilution was used to visualize ACTN4 expression in cells. Images were taken with Axiovert Zeiss fluorescent microscope. 


\section{RESULTS}

\section{Three-Dimensional Collagen I Culture Alters the Transcriptome of Ovarian Cancer Cells}

Metastasizing ovarian cancer cells encounter a submesothelial matrix rich in interstitial type I collagen. We have previously demonstrated that cells cultured on two-dimensional vs 3DCI surfaces exhibit similar adhesion profiles; however, cells align with collagen fibrils on 3DCI and dramatic changes in cell morphology are accompanied by increased invasion. ${ }^{12}$ As invasion requires coordinated activity of adhesion molecules, matrix modifiers and the motility apparatus, we postulated that 3DCI culture may regulate expression of genes related to these processes. To generate a comprehensive picture of EOC cellular response to 3DCI culture, comparative cDNA microarray analysis with an array containing oligonucleotides corresponding to $12.5 \mathrm{~K}$ known human genes was used to analyze gene expression in EOC cells cultured on thin-layer collagen I (2DCI) relative to cells cultured on 3DCI gels. Statistical analysis yielded 31 genes that were greater than twofold differentially expressed between the sample (cells cultured atop 3DCI) and control (cells cultured on 2DCI) with $P<0.05$ (Table 2). Candidate genes were validated using real-time RT-PCR. Five genes of eight tested were significantly ( $>2$-fold) upregulated by three-dimensional collagen culture conditions (ACTN4, JUNB, MXI1, SLC20A1, TNFSF10; Figure 1a), whereas four genes (CLDN1, HHEX, IL6, TGFB2; Figure 1b) among five tested were downregulated by 3DCI culture conditions. Although differential expression of several of the genes identified using this protocol has been associated previously with cancer progression and/or metastasis (Table 3), most of these genes were not previously associated with ovarian cancer.

\section{ACTN4 Expression is Gained in Advanced Human Ovarian Carcinoma and Peritoneal Metastases}

Among the genes identified using this protocol, actinin alpha- 4 has been extensively associated with cell motility in breast, colorectal and lung carcinomas (Table 3). ${ }^{58-60}$ The increase of ACTN4 mRNA was confirmed at the protein level in cells cultured on 3DCI using western blotting (Figure 2). As a goal of the study was to identify genes not previously associated with ovarian cancer invasion and motility, ACTN4 expression and function in EOC cells and tissues was evaluated in detail. Initial experiments utilized real-time RT-PCR analysis of ACTN4 expression in normal ovarian epithelium and EOC of various stages (Figure 3a). Specimens of advanced-stage ovarian tumors were overwhelmingly positive (77\%) for ACTN4, whereas expression was detected in only 33 and $42 \%$ of early-stage tumors and normal ovarian epithelium, respectively. Expression of control genes RPL-19 and $A C T N B$ was detected in all samples (Figure $3 \mathrm{~b}$ and $\mathrm{c}$ ). These results show that expression of ACTN4 mRNA is elevated in advanced ovarian carcinoma.

Complementary immunohistochemical analyses of ACTN4 expression in primary EOC and paired metastatic lesions from the same patient was also employed (Table 4; Figure 4). ACTN4 expression was detected in 100\% of metastatic lesions, whereas $76 \%$ of corresponding primary tissues exhibited ACTN4 expression. In $88 \%$ of paired samples, expression of ACTN4 in the metastatic lesion was greater than or equal to that observed in the primary tumor. Of particular note, in four cases, primary specimens did not express ACTN4, whereas the matched metastatic samples were ACTN4 positive. These data demonstrate that ACTN4 expression is gained or increased over primary in metastatic ovarian carcinoma tissues.

\section{ACTN4 Functions in Promoting Ovarian Carcinoma Invasion and Motility}

The ability of malignant cells to migrate and invade are key properties that allow ovarian tumor cells to anchor secondary extra-ovarian lesions. ${ }^{16}$ To examine the role of ACTN4 in these processes, wild-type EOC cells or those transfected with either control or ACTN4-specific siRNA were evaluated for the ability to invade three-dimensional collagen gels in a modified Boyden chamber invasion assay. Cells in which ACTN4 expression was silenced with siRNA exhibited a greater than $50 \%$ reduction in invasive activity relative to wild-type or control siRNA-transfected cells (Figure 5a). These cells are known to utilize the collagenolytic enzyme MT1-MMP to penetrate collagen gels, ${ }^{14,44}$ and we have previously shown that collagen-induced MT1-MMP expression is regulated primarily through an increase in the transcription factor Egr-1. ${ }^{12}$ Indeed, down-modulation of ACTN4 expression did not alter MT1-MMP levels (Figure 5b), whereas the efficiency of silencing of the ACTN4 gene expression on the protein level was about $45 \%$ (Figure $5 \mathrm{~b}$ ). These data indicate that 3DCI activates a transcriptional program to coordinate expression of molecular mediators of two key components of the invasive process, matrix modifiers (ie, MT1-MMP) and the motility apparatus (ie, ACTN4).

As the data above indicate that altered collagen invasion was not due to effects of ACTN4 on MT1-MMP expression, the ability of ACTN4 to regulate cellular motility ${ }^{58-60}$ was tested using a scratch wound assay. Migration of ACTN4silenced cells was significantly reduced compared with that of control cells (Figure $6 \mathrm{a}$ and b). Further, immunocytochemical staining demonstrated ACTN4 upregulation in ovarian cancer cells migrating at the wound edge ${ }^{58}$ (Figure 6c and d). In contrast, in cells forming a monolayer, ACTN4 was predominantly found in the endoplasmic reticulum and exhibited only weak staining in the cytoplasm and nucleus (Figure 6d).

\section{DISCUSSION}

The high mortality of advanced ovarian cancer is due predominantly to intraperitoneal metastasis; however, the mechanisms that control metastatic spread are largely unexplored. Aberrant gene expression due to mutation, epigenetic changes and microenvironmental factors may 
Table 2 Genes found to be differentially expressed in DoV13 ovarian cancer cells cultured on 3DCI in comparison to those on 2DCI by cDNA microarray

\begin{tabular}{|c|c|c|c|c|}
\hline Gene symbol & Gene name & $\begin{array}{l}\text { Genbank } \\
\text { accession no. }\end{array}$ & Fold change & $P$-value \\
\hline \multicolumn{5}{|c|}{ Upregulated by three-dimensional collagen I } \\
\hline $\mathrm{FBXO10^{ \textrm {a } }}$ & F-box protein 10 & AF176705 & 4.32 & 0.000397 \\
\hline TSC22D1 & TSC22 domain family, member 1 & NM_006022 & 3.99 & $6.48 \mathrm{E}-05$ \\
\hline HSPA8 & Heat shock 70 kDa protein 8 & NM_006597 & 3.97 & 0.001843 \\
\hline TXNIPb & Thioredoxin-interacting protein & NM_006472 & 3.58 & 0.000364 \\
\hline ACTN4 ${ }^{C}$ & Actinin, alpha 4 & NM_004924 & 3.30 & 0.003436 \\
\hline MMP14 & Matrix metallopeptidase 14 (membrane-inserted) & NM_004995 & 2.97 & 0.016573 \\
\hline TNFSF10 & Tumor necrosis factor (ligand) superfamily, member 10 & NM_003810 & 2.88 & 0.000932 \\
\hline EEF1A1 & Eukaryotic translation elongation factor 1 alpha 1 & X03689 & 2.47 & 0.019204 \\
\hline ARRDC3 & Arrestin domain containing 3 & AB037797 & 2.40 & 0.005981 \\
\hline$J_{U N B^{C}}$ & jun B proto-oncogene & NM_002229 & 2.37 & 0.000133 \\
\hline C5orf13 (or P311) & Chromosome 5 open reading frame 13 & NM_004772 & 2.15 & 0.000975 \\
\hline CXCR4 & Chemokine (C-X-C motif) receptor 4 & NM_003467 & 2.13 & 0.014398 \\
\hline ARL4C & ADP-ribosylation factor-like $4 \mathrm{C}$ & NM_005737 & 2.04 & 0.000932 \\
\hline SLC20A $1^{c}$ & Solute carrier family 20 (phosphate transporter), member 1 & NM_005415 & 2.03 & 0.011872 \\
\hline$M X I 1^{c}$ & MAX interactor 1 & NM_005962 & 2.01 & 0.013323 \\
\hline BRAP & BRCA1-associated protein & NM_006768 & 2.01 & 0.004956 \\
\hline
\end{tabular}

Downregulated by three-dimensional collagen I

\begin{tabular}{|c|c|c|c|c|}
\hline BTBD2 & BTB (POZ) domain containing 2 & NM_017797 & 0.49 & 0.001892 \\
\hline KRT18 & Keratin 18 & L32537 & 0.49 & 0.004264 \\
\hline $\mathrm{CHIC}^{\mathrm{a}}$ & Cysteine-rich hydrophobic domain 2 & NM_012110 & 0.49 & 0.004432 \\
\hline LOC727805 & $\begin{array}{l}\text { Similar to nuclear envelope pore membrane protein POM } 121 \\
\text { (pore membrane protein of } 121 \mathrm{kDa} \text { ) (P145) }\end{array}$ & Z70717 & 0.49 & 0.006833 \\
\hline OGFRL1 & Opioid growth factor receptor-like 1 & AK024732 & 0.45 & 0.003436 \\
\hline $\mathrm{CLDN} 1^{\mathrm{C}}$ & Claudin 1 & AF101051 & 0.43 & 0.000412 \\
\hline HHEX & Homeobox, hematopoietically expressed & NM_002729 & 0.43 & 0.001784 \\
\hline HBEGF & Heparin-binding EGF-like growth factor & NM_001945 & 0.41 & 0.000612 \\
\hline DKK1 & Dickkopf homolog 1 & NM_012242 & 0.38 & 0.004956 \\
\hline ESM1 & Endothelial cell-specific molecule 1 & NM_007036 & 0.35 & 0.000288 \\
\hline AHR & Aryl hydrocarbon receptor & NM_001621 & 0.34 & 0.002139 \\
\hline ZFHX4 & Zinc-finger homeodomain 4 & AK024633 & 0.33 & 0.000257 \\
\hline THBD & Thrombomodulin & NM_000361 & 0.32 & 0.000364 \\
\hline TGFB2 $^{\mathrm{C}}$ & Transforming growth factor, beta 2 & NM_003238 & 0.31 & 0.000378 \\
\hline $\operatorname{IL} 6^{\mathrm{C}}$ & Interleukin 6 (interferon, beta 2) & M14584 & 0.26 & $6.48 \mathrm{E}-05$ \\
\hline
\end{tabular}

\footnotetext{
${ }^{a}$ No change of mRNA expression detected by real-time RT-PCR.

${ }^{\mathrm{b}}$ No product was detected with real-time RT-PCR.

${ }^{\mathrm{C}}$ See Figure 1 for genes, up- or downregulated by the three-dimensional collagen I culture as detected by real-time RT-PCR.
}

influence the malignant phenotype. The goal of this study was to develop a system by which changes in gene expression that occur as a result of interaction between metastatic cells and a three-dimensional collagen matrix to model intraperitoneal metastasis could be evaluated. Although cDNA microarrays have been used in the past to identify novel 


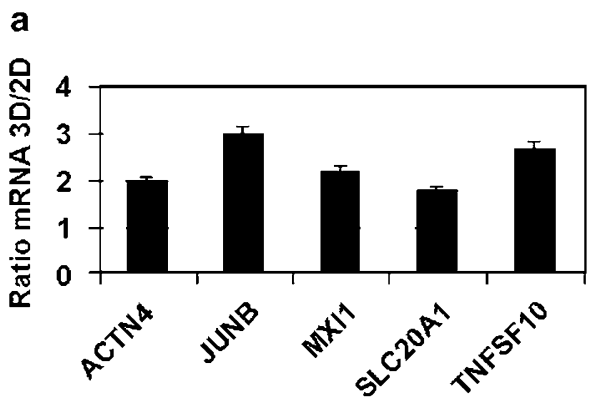

b

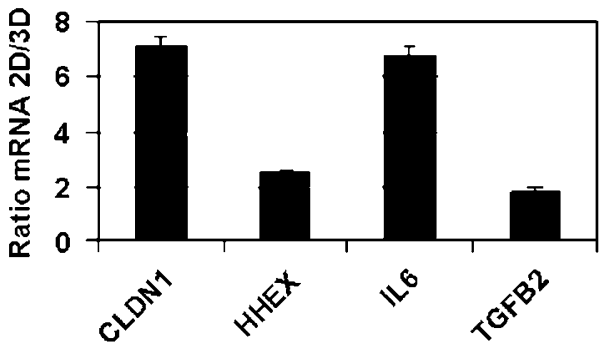

Figure 1 Three-dimensional collagen culture induces changes in gene expression. Real-time RT-PCR analysis of expression of genes (a) upregulated and (b) downregulated by the three-dimensional collagen I culture compared with two-dimensional collagen I. Actinin alpha-4 (ACTN4), jun B proto-oncogene (JUNB), MAX interactor 1 (MXI1), solute carrier family 20 (SLC20A1), tumor necrosis factor (ligand) superfamily member 10 (TNFSF10), claudin-1 (CLDN1), hematopoietically expressed homeobox (HHEX), interleukin 6 (IL6), and transforming growth factor beta 2 (TGFB2) expression was examined in cells cultured on thin-layer (2D) and three-dimensional (3D) collagen I gel for $8 \mathrm{~h}$. Total RNA was purified, cDNA synthesized and quantitative real-time RT-PCR carried out as described in Materials and methods. Results are plotted as the expression ratio, indicating the fold change of mRNA expression in cells cultured on (a) 3DCI relative to thin-layer collagen or (b) thin-layer collagen relative to $3 \mathrm{DCl}$. Data are shown as mean \pm standard deviation and are an average of three independent experiments. ovarian cancer and metastasis-related genes in patient cells and tissues, ${ }^{33-36,38-41}$ this study utilized a homogeneous cell population to avoid contamination by signals derived from stromal cells and to focus specifically on the cellular response to a major microenvironmental cue, 3-dimensional collagen. Although there are certain limitations to this approach relative to the use of patient-derived material for cDNA microarray, validation of specific genes of interest using realtime RT-PCR and immunohistochemical analysis of patient tissues ensures relevance of the findings to human disease.
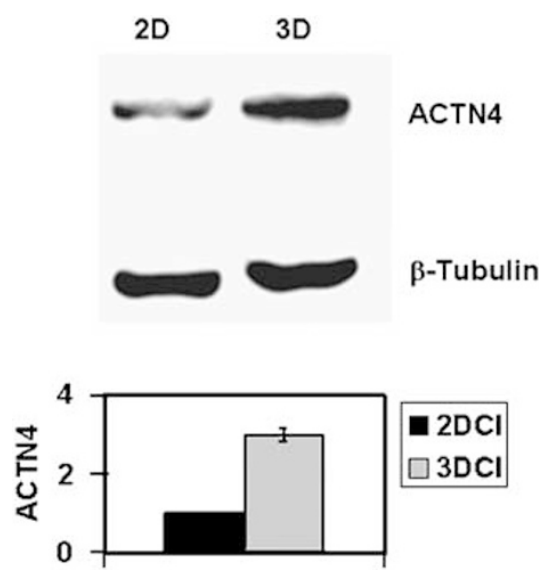

Figure 2 Actinin alpha-4 protein is upregulated by three-dimensional collagen culture. Cells were cultured on $3 \mathrm{DCl}$ and $2 \mathrm{DCl}$ for $24 \mathrm{~h}$ followed by western blot analysis of the cell lysates for ACTN4 expression. $\beta$-Tubulin was used as a loading control. Primary antibodies against ACTN4 and $\beta$-tubulin were used at 1:200 and 1:2000 dilutions, respectively. Secondary peroxidase conjugated anti-goat and anti-mouse IgG were used at 1:1000 and 1:2000 dilutions, respectively, to visualize ACTN4 and $\beta$-tubulin. The histogram shows the levels of ACTN4 expression in DOV13 cultured on 2DCl and 3DCl relative to the $\beta$-tubulin expression. The data represent an average of three independent experiments with a standard deviation $\pm 5 \%$.

Table 3 Genes, up- or downregulation of which is associated with cancer or cancer metastasis

Gene Known up/downregulation associated with cancer

Genes upregulated in cells cultured on $3 D C I$ vs $2 D C l$

$\begin{array}{ll}\text { ACTN4 } & \text { Colorectal cancer; }{ }^{32} \text { breast carcinoma; }{ }^{18} \text { lung carcinoma } \\ \text { MMP-14 } & \text { Reviewed in refs. } 33-37 \\ \text { JUNB } & \text { T-cell lymphoma }{ }^{45} \\ \text { MXI1 } & \begin{array}{l}\text { Suppressor gene in melanoma, } \\ { }^{47} \text { glioblastoma }^{48} \text { and } \\ \end{array} \\ & \text { prostate cancer cells }{ }^{49}\end{array}$

Genes downregulated in cells cultured on $3 D C l$ vs $2 D C l$

$\begin{array}{ll}\text { KRT18 } & \text { Breast cancer }^{50-52} \\ \text { CLDN1 } & \text { Endometrioid adenocarcinoma } \\ \text { TGFB2 } & \end{array}$

Known up/downregulation associated with cancer metastasis

\author{
Colorectal cancer; ${ }^{32}$ breast carcinoma ${ }^{18}$ \\ Breast ${ }^{38-40}$ hepatocellular carcinoma; ${ }^{41}$ cervical cancer; ${ }^{42}$ laryngeal \\ cancer; ${ }^{43}$ colorectal $^{44}$ \\ Breast; ${ }^{46}$ ovarian carcinoma (endometrioid hystotype) ${ }^{30}$ \\ Has not been associated with metastasis
}


a

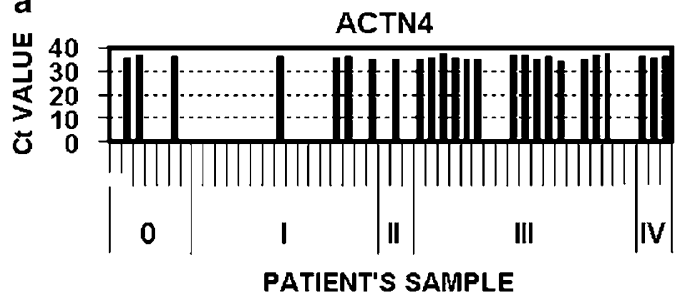

b
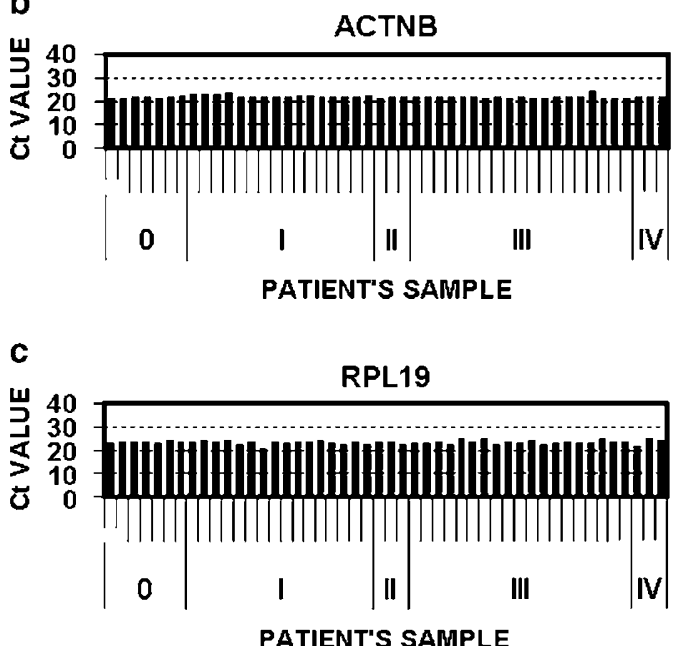

Figure 3 Real-time RT-PCR analysis of ACTN4 mRNA expression in normal ovarian epithelium and EOCs of various histological type and stage of tumorigenic development. (a) ACTN4 expression in ovarian carcinoma tissues and normal ovarian epithelia. (b, c) Expression of two housekeeping genes, $\beta$-actin (ACTNB) and ribosomal protein L19 (RPL-19), respectively. Black bars in the histograms represent the values of the cycle numbers at which the accumulation of fluorescent signal from SYBR Green bound to the gene-specific double-stranded DNA PCR product was above the background. Absence of the black bars indicates no accumulation of the PCR product specific to ACTN4. A total of 48 samples was tested for the expression of ACTN4, ACTNB and RPL-19. Results for samples from 1-48 are plotted from left to right on the $x$ axis and separated by small ticks. Samples from normal epithelia are designated as ' 0 ', and those belonging to ovarian carcinoma FIGO stages I, II, III and IV are indicated as 'I', 'II', 'III' and 'IV', respectively, and are separated by long ticks.

The current three-dimensional cell culture model has identified several differentially expressed genes previously associated with tumor progression and metastasis in other cancers. For example, MT1-MMP is an important pericellular collagenase with a diversity of extracellular substrates ${ }^{37}$ expression of which has been linked to tumor progression and metastasis. ${ }^{12,15,42,43,47,50-52,56,61-65}$ MT1MMP is a primary proteinase responsible for collagen cleavage and invasion of ovarian cancer cells ${ }^{13-15}$ and has been previously shown to be upregulated by three-dimensional collagen I culture in ovarian cancer cells. ${ }^{12,13}$ Upregulation of the transcription factor jun B proto-oncogene (JUNB) has also been previously associated with endometrioid ovarian tumors; ${ }^{33}$ however, the functional role of JUNB has not been fully elucidated.
Table 4 Expression of ACTN4 in primary and metastatic ovarian carcinoma specimens

\begin{tabular}{|c|c|c|c|}
\hline Case no. ${ }^{a}$ & Site & & $\mathrm{ACTN}^{\mathrm{b}}$ \\
\hline \multirow[t]{2}{*}{1} & Primary & $\mathrm{Neg}$ & \\
\hline & Metastasis & $3+f$ & \\
\hline \multirow[t]{2}{*}{2} & Primary & $3+d$ & \\
\hline & Metastasis & $3+f$ & \\
\hline \multirow[t]{2}{*}{3} & Primary & $2+f$ & \\
\hline & Metastasis & $2+f$ & \\
\hline \multirow[t]{2}{*}{4} & Primary & $\mathrm{Neg}$ & \\
\hline & Metastasis & $2+d$ & \\
\hline \multirow[t]{2}{*}{5} & Primary & $3+f$ & \\
\hline & Metastasis & $1+d$ & \\
\hline \multirow[t]{2}{*}{6} & Primary & $2+d$ & \\
\hline & Metastasis & $3+d$ & \\
\hline \multirow[t]{2}{*}{7} & Primary & $2+f$ & \\
\hline & Metastasis & $3+d$ & \\
\hline \multirow[t]{2}{*}{8} & Primary & $3+d$ & \\
\hline & Metastasis & $1+d$ & \\
\hline \multirow[t]{2}{*}{9} & Primary & $3+d$ & \\
\hline & Metastasis & $3+d$ & \\
\hline \multirow[t]{2}{*}{10 endometrioid } & Primary & $2+d$ & \\
\hline & Metastasis & $2+d$ & \\
\hline \multirow[t]{2}{*}{11} & Primary & $2+d$ & \\
\hline & Metastasis & $2+d$ & \\
\hline \multirow[t]{2}{*}{12 endometrioid } & Primary & $2+d$ & \\
\hline & Metastasis & $2+f$ & \\
\hline \multirow[t]{2}{*}{13} & Primary & Neg & \\
\hline & Metastasis & $2+d$ & \\
\hline \multirow[t]{2}{*}{14} & Primary & $1+d$ & \\
\hline & Metastasis & $2+d$ & \\
\hline \multirow[t]{2}{*}{15} & Primary & $\mathrm{Neg}$ & \\
\hline & Metastasis & $2+d$ & \\
\hline \multirow[t]{2}{*}{16} & Primary & $2+d$ & \\
\hline & Metastasis & $3+d$ & \\
\hline \multirow[t]{2}{*}{17} & Primary & $1+d$ & \\
\hline & Metastasis & $1+d$ & \\
\hline
\end{tabular}

${ }^{\mathrm{a}} \mathrm{A}$ total of 15 tumors belonged to serous histotype, two tumors (case no. 10 and 12) were of endometrioid histological type, as indicated.

${ }^{\mathrm{b}}$ ACTN4 staining intensity is described as negative (neg), $1+$ (weakly positive), $2+$ (positive), 3+ (strong positive), and as focal (f) or diffuse (d), as described in Materials and methods. Increase of ACTN4 staining in paired metastatic specimens in comparison with primary is indicated by an arrow pointing up $(\uparrow)$, whereas a decrease or no change was indicated with arrow pointing down $(\downarrow)$ and an 'equal' sign $(=)$ respectively.

Many of the genes differentially regulated by threedimensional collagen culture have not been reported in association with ovarian carcinoma but are known to have 
a
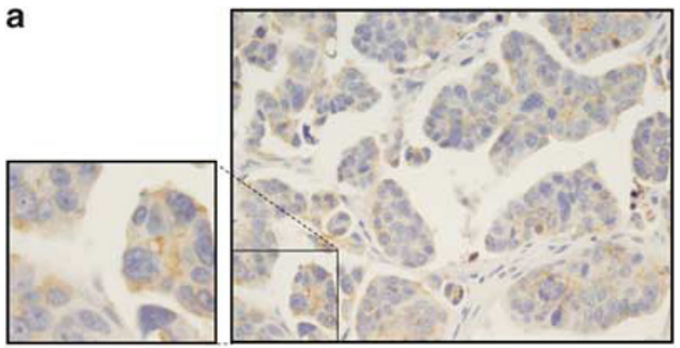

b
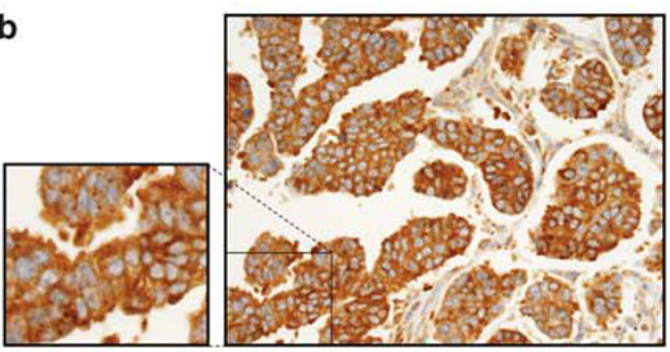

Figure 4 Immunohistochemical analysis of ACTN4 expression in paired primary and metastatic human EOCs. (a, b) Representative example of paired (a) primary tumor and (b) the corresponding metastatic lesion from the same patient. Tissues were stained with ACTN4-specific antibodies as indicated in Materials and methods. In both primary and metastatic specimens, cytoplasmic staining with ACTN4 antibodies was detected (ACTN4-brown; nuclear DNA-hematoxylin \& eosin); Insets show magnified representative portions of the stained tissue.

functional significance in other tumor models. For example, KRT18 mRNA was decreased by 3DCI culture in EOC cells. Interestingly, overexpression of KRT18 in breast carcinoma is correlated with a favorable prognosis, and forced overexpression of KRT18 led to regression of malignant phenotype. ${ }^{48,49,66}$ Studies of recurrent and metastatic breast carcinomas have shown that a component of tight junctions, claudin-1 (CLDN1), showed decreased expression patterns compared with non-recurrent group. ${ }^{67}$ Loss of claudin-1 expression in prostatic adenocarcinoma correlated with high tumor grade and disease recurrence. ${ }^{68}$ It is not known whether the downregulation of CLDN1 has a role in metastatic ovarian cancers; however, the positive expression of this protein has been reported in primary ovarian adenocarcinomas. ${ }^{69}$ Downregulation of TGF $\beta 2$ has been reported for metastatic compared with primary oral squamous cell carcinoma in genomewide screening of eight pairs of microdissected samples, ${ }^{70}$ and similarly, in our experiments, 3 DCI culture downregulated TGF $\beta 2$ on the RNA level; however, the significance of this observation remains unclear in both malignancies. Expression of IL6 was associated with favorable prognosis in ovarian cancer patients, ${ }^{71}$ and hence downregulation of IL6 mRNA in cells cultured on 3DCI may be an indicator of tumor progression.

Malignant transformation is characterized by changes in proliferative, pro-survival and apoptotic mechanisms. ${ }^{16}$ Ovarian cancer cells cultured in 3DCI exhibited upregulation of the Max interactor protein 1 (MXI1) that affects cell

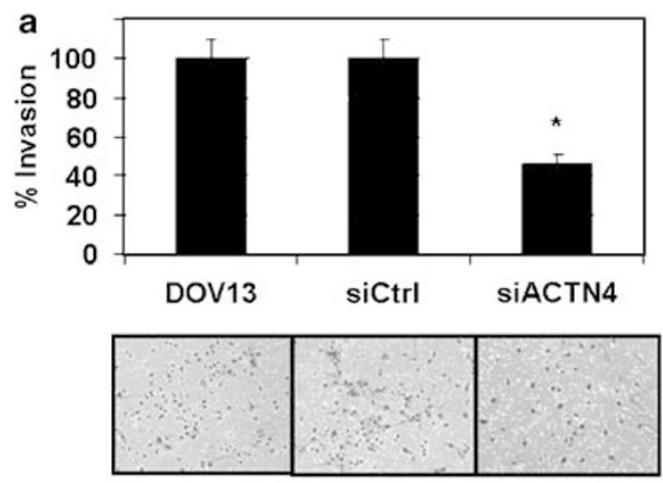

b

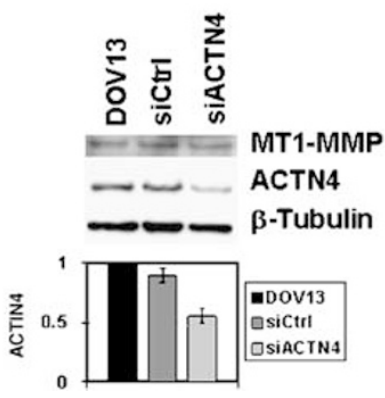

Figure 5 ACTN4 gene silencing retards ovarian cancer invasion through three-dimensional collagen. (a) Boyden chamber 3D collagen invasion assay. DOV13 cells were transfected with siRNA for ACTN4 or control siRNA, as indicated, and invasion of collagen gels was evaluated in a modified Boyden chamber assay as described in Materials and methods. Histograms show a percentage of invading cells, with invasion of wild-type cells designated as $100 \%$. Data represent an average of three independent experiments. Representative bright field images of cells invading to the underside of the filter are shown below the histograms. (b) ACTN4 does not affect MT1-MMP expression (upper panel). Cells were transfected with ACTN4 and control siRNA, and the cell lysates were examined for MT1-MMP expression by western blot (1:1000 dilution of anti-MT1-MMP, 1:4000 dilution of peroxidase conjugated anti-rabbit $\operatorname{lgG}$ ). ACTN4 siRNA is efficient in silencing the ACTN4 gene expression (middle panel) (1:200 dilution of anti-ACTN4, 1:1000 dilution of peroxidase conjugated anti-goat lgG). The histogram at the bottom demonstrates levels of ACTN4 expression in untransfected DOV13 (black bar) compared with those transfected with control siRNA (dark gray bar) and ACTN4 siRNA (light gray bar). The data represent an average of two independent experiments with a standard deviation $\pm 10 \%$. The asterisk shows significant differences to the control with $P \leq 0.005$.

proliferation through transcriptional repression of c-Mycregulated genes ${ }^{72}$ and has been suggested to function as a tumor suppressor in melanoma, ${ }^{73}$ glioblastoma ${ }^{74}$ and human prostate cells. ${ }^{75}$ Furthermore, TRAIL was capable of killing DOV13 cells in vitro, ${ }^{76}$ and our data indicate upregulation of TRAIL mRNA by 3DCI culture conditions. Paradoxically, however, DOV13 and several other ovarian cancer cell lines cultured on 3DCI survived significantly longer than those cultured on 2DCI in serum-free conditions (M.V.B and M.S.S, unpublished data), implying that a more detailed examination of apoptotic and necrotic mechanisms is necessary to establish a role for 3DCI in the regulation of programmed death mechanisms. 


\section{a}
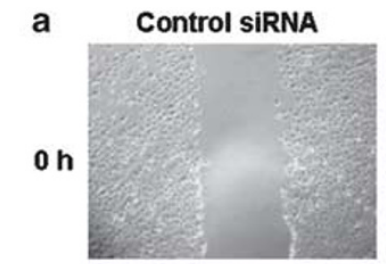

$50 \mathrm{~h}$
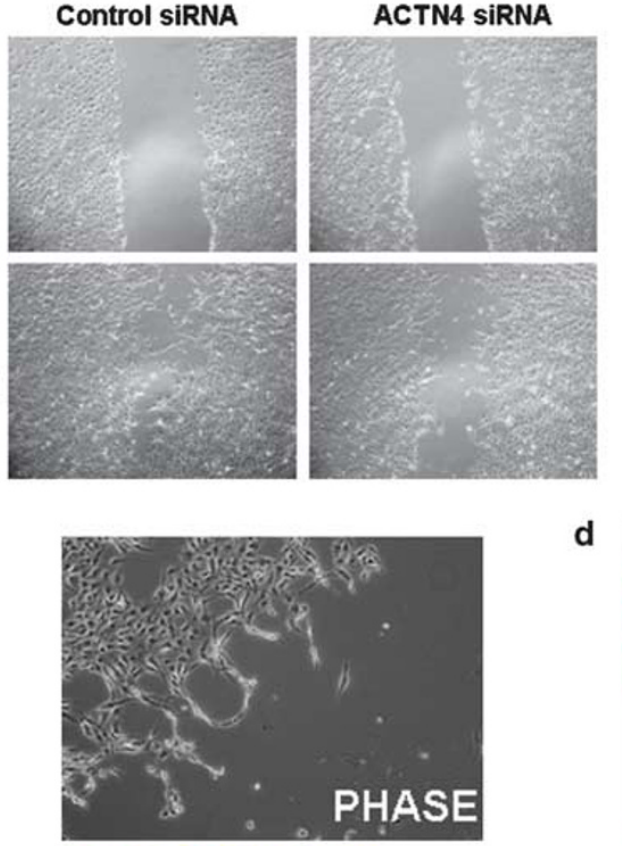

C
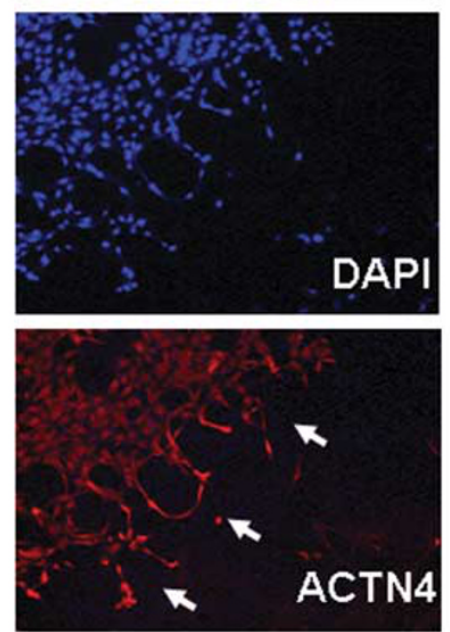

b

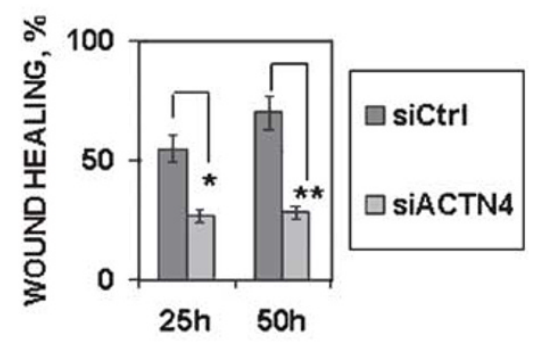

d
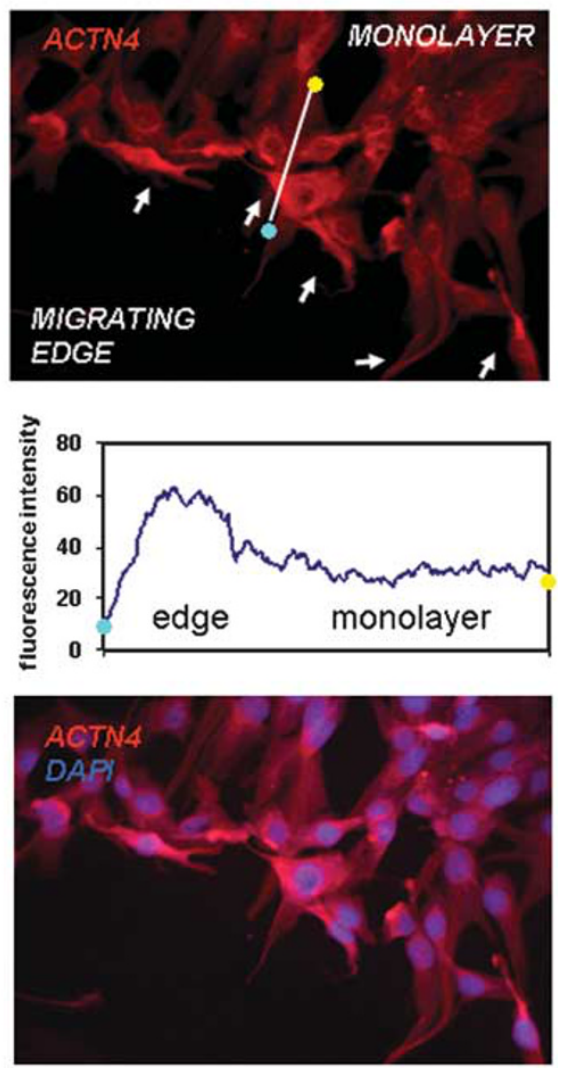

Figure 6 ACTN4 gene silencing retards ovarian cancer cell motility. (a) Scratch wound motility assay. DOV13 cell monolayers were wounded and observed over the indicated periods of time, 25 and $50 \mathrm{~h}$. Note that cell motility of DOV13 transfected with phosphate-buffered saline was the same as that for cells transfected with the control siRNA, and hence the former are not shown. Photographs of the wounds are representative of three independent experiments that were performed and quantified as indicated in Materials and methods and are taken at $\times 5$ magnification. (b) Histograms illustrate the percentage of cell motility in the wound-healing assay with the standard deviation of $\pm 10 \%$. Dark gray and light gray bars represent $\%$ of wound healing in cell monolayers transfected with control and ACTN4 siRNA, respectively. ${ }^{*} P \leq 0.006,{ }^{*} P \leq 0.012$. (c) ACTN4 is upregulated in cells on the edge of the healing wound. Wounds were introduced in cell monolayers cultured in standard conditions on glass coverslips coated with collagen I, allowed to migrate for $20 \mathrm{~h}$, fixed and stained with DAPI and ACTN4-specific antibody as indicated in the Materials and methods. Photographs of cells in phase, DAPI- and ACTN4-fluorescence, were taken at $\times 5$ magnification on the objective using a Zeiss Axiovert fluorescent microscope, as indicated. White arrows indicate the position of the migrating edge of the cell monolayer and an increase in ACTN4 expression in migrating cells. (d) Cytoplasmic staining of ACTN4 in migrating cells. Cells cultured on collagen-coated glass coverslips were induced to migrate in a scratch wound assay for $20 \mathrm{~h}$, fixed and stained with ACTN4 antisera (1:100 dilution), Alexa 488 phallö̈din (red) and DAPI (blue) as indicated in Materials and methods. Photographs were taken with Zeiss Axiovert fluorescent microscope at $\times 40$ magnification on the objective. White arrows show cytoplasmic localization of ACTN4 in migrating cells. A white line is drawn starting from the migrating edge (marked with a cyan dot) toward the monolayer (marked with a yellow dot) to compare the intensity of intracellular ACTN4 staining. Intensity of the ACTN4 staining is quantified using ImageJ (NIH). Cyan and yellow dots on the graph correspond to the beginning and the end of the line drawn to generate the intensity scan. 
To evaluate a potential functional link between cellular interaction with 3DCI and enhanced motility and/or invasion, the role of ACTN4 in these processes was evaluated in detail. Multiple functions have been reported for ACTN4, including interaction with plasminogen activator inhibitor type-1, which may prevent ACTN4 proteolytic cleavage and thereby block mononuclear phagocyte response, resulting in tumor cell survival. ${ }^{77}$ It has been shown that ACTN4 regulates AKT1 localization and function and regulates cell proliferation. ${ }^{78}$ Direct interaction of ICAM-1 with ACTN4 has been reported to be essential for leukocyte extravasation. ${ }^{79}$ ACTN4 has also been shown to bind the hemidesmosomal component BP180, establishing a role for ACTN4 in cell-matrix interactions. ${ }^{80}$ Intriguingly, controversial data regarding the function of ACTN4 as motility-associated gene have been reported to date. The presence of cytoplasmic ACTN4 in breast cancer cells has been associated with higher motility and a more invasive phenotype. $^{58}$ Similarly, in colorectal cancer, ACTN4 increased cell motility and promoted lymph node metastasis ${ }^{59}$, whereas in lung carcinoma, a mutant ACTN4 was not able to support cell migration. ${ }^{60}$ However, studies of mice genetically deficient in ACTN4 expression have shown increased lymphocyte chemotaxis. ${ }^{81}$ Further, overexpression of ACTN4 led to the suppression of neuroblastoma growth in nude mice. $^{82}$ Our results support those in breast, colorectal and lung carcinomas, wherein ACTN4 expression regulates invasion through modulation of cellular motility. Interestingly, it has been shown that expression of ACTN4 was detected in adherent neuroblastoma cells but was reduced in non-adherent neuroblastoma cells. ${ }^{82}$ Thus, the paradoxical functions of ACTN4 in adherent (breast, ${ }^{27}$ lung, ${ }^{60}$ colorectal, ${ }^{31}$ ovarian carcinoma) and non-adherent cells (lymphocytes, ${ }^{71}$ malignant, poorly substrate-adherent neuroblastoma ${ }^{82}$ ) could be related to morphological alterations leading to differential interactions with other cytoskeletal proteins. Additional studies are necessary to fully elucidate the functional role of ACTN4 in tumor progression and metastasis.

To date, little information is available regarding transcriptional control of ACTN4 expression. The current report is the first study describing upregulation of ACTN4 through the interaction of cells with a three-dimensional extracellular matrix. Although the detailed mechanism of this regulatory pathway remains to be elucidated, dramatic changes in ovarian cancer cell morphology induced by three-dimensional collagen I culture ${ }^{12}$ may lead to ACTN4 overexpression through alterations in matrix- and/or mechano-signaling pathways. Migrating cells may utilize both proteolytic and nonproteolytic (or amoeboid) ${ }^{83-86}$ mechanisms to navigate to sites where metastatic growth is supported by the microenvironment. Cytoskeleton-associated proteins are likely to play a role in supporting both of these mechanisms. The elevated expression of ACTN4 in ovarian tumor metastases indicates that further studies on the role of this protein in promotion of cell migration and subsequent establishment of metastases may provide novel insight into mechanisms of ovarian cancer dissemination.

Supplementary Information accompanies the paper on the Laboratory Investigation website (http://www.laboratoryinvestigation.org)

\section{ACKNOWLEDGEMENT}

We thank Dr Peter Penzes for critical reading of the manuscript and assistance with the ImageJ program and Dr Jonathan Jones for helpful discussions. The authors gratefully acknowledge the research support by 2005-2006 and 2007-2008 Penny Severns Breast, Cervical and Ovarian Cancer Fund grant from the Illinois Department of Public Health (to MVB), 2006 Ovarian Cancer Research Foundation Program of Excellence award (to MVB), 2007 Katten Muchin Rosenman Travel Scholarship Award from RH Lurie Comprehensive Cancer center of Northwestern University (to MVB) and National Cancer Institute Research Grant RO1 CA86984 (to MSS).

1. Dupont NC, Berman ML. Surgical management of epithelial ovarian cancer: a review of the literature. Minerva Ginecologica 2004;56: 547-556.

2. Guppy $A E$, Nathan PD, Rustin GJ. Epithelial ovarian cancer: a review of current management. Clin Oncol (R Coll Radiol) 2005;17:399-411.

3. Jemal A, Siegel R, Ward E, et al. Cancer statistics, 2006. CA: A Cancer Journal for Clinicians 2006;56:106-130.

4. Runnebaum IB, Stickeler E. Epidemiological and molecular aspects of ovarian cancer risk. J Cancer Res Clin Oncol 2001;127:73-79.

5. Sankaranarayanan R, Ferlay J. Worldwide burden of gynaecological cancer: the size of the problem. Best Pract Res Clin Obstet Gynaecol 2006;20:207-225.

6. Cannistra SA. Cancer of the ovary. N Engl J Med 1993;329:1550-1559.

7. Aletti GD, Gallenberg MM, Cliby WA, et al. Current management strategies for ovarian cancer. Mayo Clin Proc 2007;82:751-770.

8. Ryerson $A B$, Eheman $C$, Burton J, et al. Symptoms, diagnoses, and time to key diagnostic procedures among older U.S. women with ovarian cancer. Obstet Gynecol 2007;109:1053-1061.

9. Pectasides $D$, Pectasides $M$, Economopoulos $T$. Brain metastases from epithelial ovarian cancer: a review of the literature. Oncologist 2006;11:252-260.

10. Fishman DA, Chilukuri K, Stack MS. Biochemical characterization of primary peritoneal carcinoma cell adhesion, migration, and proteinase activity. Gynecol Oncol 1997;67:193-199.

11. Moser TL, Pizzo SV, Bafetti LM, et al. Evidence for preferential adhesion of ovarian epithelial carcinoma cells to type I collagen mediated by the alpha2beta1 integrin. Int J Cancer 1996;67:695-701.

12. Barbolina MV, Adley BP, Ariztia EV, et al. Microenvironmental regulation of membrane type 1 matrix metalloproteinase activity in ovarian carcinoma cells via collagen-induced EGR1 expression. J Biol Chem 2007;282:4924-4931.

13. Ellerbroek SM, Fishman DA, Kearns AS, et al. Ovarian carcinoma regulation of matrix metalloproteinase- 2 and membrane type 1 matrix metalloproteinase through beta1 integrin. Cancer Res 1999;59: 1635-1641.

14. Ellerbroek SM, Wu $\mathrm{Yl}$, Overall $\mathrm{CM}$, et al. Functional interplay between type I collagen and cell surface matrix metalloproteinase activity. J Biol Chem 2001;276:24833-24842.

15. Ellerbroek SM, Wu Yl, Stack MS. Type I collagen stabilization of matrix metalloproteinase-2. Arch Biochem Biophys 2001;390:51-56.

16. Hanahan D, Weinberg RA. The hallmarks of cancer. Cell 2000; 100:57-70.

17. Yamada KM, Cukierman E. Modeling tissue morphogenesis and cancer in 3D. Cell 2007;130:601-610.

18. Batrakova EV, Kelly DL, Li S, et al. Alteration of genomic responses to doxorubicin and prevention of MDR in breast cancer cells by a polymer excipient: pluronic P85. Mol Pharm 2006;3:113-123.

19. Chan CY, Salabat MR, Ding XZ, et al. Identification and in silico characterization of a novel gene: TPA induced trans-membrane protein. Biochem Biophy Res Commun 2005;329:755-764. 
20. Smyth GK. Linear models and empirical Bayes methods for assessing differential expression in microarray experiments. Stat Appl Genet Mol Biol 2004:3:Article3.

21. Gentleman RC, Carey VJ, Bates DM, et al. Bioconductor: open software development for computational biology and bioinformatics. Genome Biol 2004;5:R80.

22. R Development Core Team. R: A Language and Environment for Statistical Computing. R Foundation for Statistical Computing, Vienna, Austria, 2008; http://www.r-project.org.

23. Yang $\mathrm{YH}$, Dudoit $\mathrm{S}$, Luu $\mathrm{P}$, et al. Normalization for CDNA microarray data: a robust composite method addressing single and multiple slide systematic variation. Nucleic Acids Res 2002;30:e15.

24. Benjamini Y, Hochberg Y. Controlling the false discovery rate: a practical and powerful approach to multiple testing. J Roy Stat Soc B 1995;57:289-300.

25. Kolbus A, Blazquez-Domingo M, Carotta S, et al. Cooperative signaling between cytokine receptors and the glucocorticoid receptor in the expansion of erythroid progenitors: molecular analysis by expression profiling. Blood 2003;102:3136-3146.

26. Halasz J, Holczbauer A, Paska C, et al. Claudin-1 and claudin-2 differentiate fetal and embryonal components in human hepatoblastoma. Human Pathol 2006;37:555-561.

27. Huber R, Kunisch E, Gluck B, et al. Vergleich zwischen konventioneller und Real-Time RT-PCR zur Quantifizierung der jun-ProtoonkogenmRNA und Analyse der junB-mRNA-Expression in Synovialmembranen und isolierten synovialen Fibroblasten von Patienten mit rheumatoider Arthritis. Zeitschrift fur Rheumatologie 2003;62:378-389.

28. Girault I, Lerebours F, Tozlu S, et al. Real-time reverse transcription PCR assay of CYP19 expression: application to a well-defined series of postmenopausal breast carcinomas. J Steroid Biochem Mol Biol 2002:82:323-332.

29. Livak KJ, Schmittgen TD. Analysis of relative gene expression data using real-time quantitative PCR and the 2(-Delta Delta C(T)) Method. Methods 2001;25:402-408.

30. Laemmli UK. Cleavage of structural proteins during the assembly of the head of bacteriophage T4. Nature 1970;227:680-685.

31. Matsudaira P. Sequence from picomole quantities of proteins electroblotted onto polyvinylidene difluoride membranes. J Biol Chem 1987;262:10035-10038.

32. Hayashida $\mathrm{Y}$, Honda $\mathrm{K}$, Idogawa $\mathrm{M}$, et al. E-cadherin regulates the association between beta-catenin and actinin-4. Cancer Res 2005;65:8836-8845.

33. Mayr D, Kanitz V, Anderegg B, et al. Analysis of gene amplification and prognostic markers in ovarian cancer using comparative genomic hybridization for microarrays and immunohistochemical analysis for tissue microarrays. Am J Clin Pathol 2006;126:101-109.

34. Meinhold-Heerlein I, Bauerschlag D, Hilpert F, et al. Molecular and prognostic distinction between serous ovarian carcinomas of varying grade and malignant potential. Oncogene 2005;24: 1053-1065.

35. Schaner ME, Ross DT, Ciaravino G, et al. Gene expression patterns in ovarian carcinomas. Mol Biol Cell 2003;14:4376-4386.

36. Schwartz DR, Kardia SL, Shedden KA, et al. Gene expression in ovarian cancer reflects both morphology and biological behavior, distinguishing clear cell from other poor-prognosis ovarian carcinomas. Cancer Res 2002;62:4722-4729.

37. Barbolina MV, Stack MS. Membrane type 1-matrix metalloproteinase: substrate diversity in pericellular proteolysis. Semin Cell Dev Biol 2007:19:24-33.

38. Donninger $\mathrm{H}$, Bonome $\mathrm{T}$, Radonovich $\mathrm{M}$, et al. Whole genome expression profiling of advance stage papillary serous ovarian cancer reveals activated pathways. Oncogene 2004;23:8065-8077.

39. Lancaster JM, Dressman HK, Whitaker RS, et al. Gene expression patterns that characterize advanced stage serous ovarian cancers. J Soc Gynecol Invest 2004;11:51-59.

40. Matei $\mathrm{D}$, Graeber TG, Baldwin RL, et al. Gene expression in epithelial ovarian carcinoma. Oncogene 2002;21:6289-6298.

41. Hibbs K, Skubitz KM, Pambuccian SE, et al. Differential gene expression in ovarian carcinoma: identification of potential biomarkers. Am J Pathol 2004;165:397-414.

42. Chabottaux V, Sounni NE, Pennington CJ, et al. Membrane-type 4 matrix metalloproteinase promotes breast cancer growth and metastases. Cancer Res 2006;66:5165-5172.
43. Bendardaf $\mathrm{R}$, Lamlum $\mathrm{H}$, Vihinen $\mathrm{P}$, et al. Low collagenase-1 (MMP-1) and MT1-MMP expression levels are favourable survival markers in advanced colorectal carcinoma. Oncology 2003;65:337-346.

44. Ellerbroek SM, Fishman DA, Kearns AS, et al. Ovarian carcinoma regulation of matrix metalloproteinase-2 and membrane type 1 matrix metalloproteinase through beta1 integrin. Cancer Res 1999;59: 1635-1641.

45. Szremska AP, Kenner L, Weisz E, et al. JunB inhibits proliferation and transformation in B-lymphoid cells. Blood 2003;102:4159-4165.

46. Langer $S$, Singer CF, Hudelist $G$, et al. Jun and Fos family protein expression in human breast cancer: correlation of protein expression and clinicopathological parameters. Eur J Gynaecol Oncol 2006;27:345-352.

47. Zhai $Y$, Hotary KB, Nan B, et al. Expression of membrane type 1 matrix metalloproteinase is associated with cervical carcinoma progression and invasion. Cancer Res 2005;65:6543-6550.

48. Buhler H, Schaller G. Transfection of keratin 18 gene in human breast cancer cells causes induction of adhesion proteins and dramatic regression of malignancy in vitro and in vivo. Mol Cancer Res: MCR 2005;3:365-371.

49. Schaller G, Fuchs I, Ebert A, et al. [The clinical importance of keratin 18 in breast cancer]. Zentralbl Gynakol 1999;121:126-130.

50. Ip YC, Cheung ST, Leung KL, et al. Mechanism of metastasis by membrane type 1-matrix metalloproteinase in hepatocellular carcinoma. World J Gastroenterol 2005;11:6269-6276.

51. Jiang WG, Davies G, Martin TA, et al. Expression of membrane type-1 matrix metalloproteinase, MT1-MMP in human breast cancer and its impact on invasiveness of breast cancer cells. Int J Mol Med 2006;17:583-590.

52. Kim HJ, Park Cl, Park BW, et al. Expression of MT-1 MMP, MMP2, MMP9 and TIMP2 mRNAs in ductal carcinoma in situ and invasive ductal carcinoma of the breast. Yonsei Med J 2006;47:333-342.

53. Sobel G, Nemeth J, Kiss A, et al. Claudin 1 differentiates endometrioid and serous papillary endometrial adenocarcinoma. Gynecol Oncol 2006;103:591-598

54. Martinez-Estrada OM, Culleres A, Soriano FX, et al. The transcription factors Slug and Snail act as repressors of Claudin-1 expression in epithelial cells. Biochem J 2006;394:449-457.

55. Tokes AM, Kulka J, Paku S, et al. Claudin-1, -3 and -4 proteins and mRNA expression in benign and malignant breast lesions: a research study. Breast Cancer Res 2005;7:R296-R305.

56. Seiki M. Membrane-type 1 matrix metalloproteinase: a key enzyme for tumor invasion. Cancer Lett 2003;194:1-11.

57. Liu CJ, Lin SC, Chen YJ, et al. Array-comparative genomic hybridization to detect genomewide changes in microdissected primary and metastatic oral squamous cell carcinomas. Mol Carcinog 2006;45: 721-731.

58. Honda K, Yamada T, Endo R, et al. Actinin-4, a novel actin-bundling protein associated with cell motility and cancer invasion. J Cell Biol 1998;140:1383-1393.

59. Honda K, Yamada T, Hayashida Y, et al. Actinin-4 increases cell motility and promotes lymph node metastasis of colorectal cancer. Gastroenterology 2005;128:51-62.

60. Menez J, Le Maux Chansac B, Dorothee G, et al. Mutant alpha-actinin-4 promotes tumorigenicity and regulates cell motility of a human lung carcinoma. Oncogene 2004;23:2630-2639.

61. Sato H, Takino T, Miyamori H. Roles of membrane-type matrix metalloproteinase-1 in tumor invasion and metastasis. Cancer Science 2005;96:212-217.

62. Seiki M, Koshikawa N, Yana I. Role of pericellular proteolysis by membrane-type 1 matrix metalloproteinase in cancer invasion and angiogenesis. Cancer Metastasis Rev 2003;22:129-143.

63. Seiki M, Yana I. Roles of pericellular proteolysis by membrane type-1 matrix metalloproteinase in cancer invasion and angiogenesis. Cancer Sci 2003;94:569-574.

64. Shiomi T, Okada Y. MT1-MMP and MMP-7 in invasion and metastasis of human cancers. Cancer Metastasis Rev 2003;22:145-152.

65. Sun YN, Li Y. Expression of mRNA for membrane-type 1, 2, and 3 matrix metalloproteinases in human laryngeal cancer. Chin Med Sci J 2004:19:170-173.

66. Schaller G, Fuchs I, Pritze W, et al. Elevated keratin 18 protein expression indicates a favorable prognosis in patients with breast cancer. Clin Cancer Res 1996;2:1879-1885. 
67. Morohashi S, Kusumi T, Sato F, et al. Decreased expression of claudin-1 correlates with recurrence status in breast cancer. Int J Mol Med 2007:20:139-143.

68. Sheehan GM, Kallakury BV, Sheehan CE, et al. Loss of claudins-1 and -7 and expression of claudins -3 and -4 correlate with prognostic variables in prostatic adenocarcinomas. Human Pathol 2007;38:564-569.

69. Zhu Y, Sundfeldt K. Tight junction formation in epithelial ovarian adenocarcinoma. Acta Obstet Gynecol Scand 2007;86:1011-1019.

70. Liu CJ, Lin SC, Chen YJ, et al. Array-comparative genomic hybridization to detect genomewide changes in microdissected primary and metastatic oral squamous cell carcinomas. MolCarcinog 2006;45: 721-731.

71. Garg R, Wollan M, Galic V, et al. Common polymorphism in interleukin 6 influences survival of women with ovarian and peritoneal carcinoma. Gynecol Oncol 2006;103:793-796.

72. Zervos AS, Gyuris J, Brent R. Mxi1, a protein that specifically interacts with Max to bind Myc-Max recognition sites.[erratum appears in Cell. 1994 Oct 21;79(2):following 388; PMID: 7954804]. Cell 1993;72: 223-232.

73. Ariyanayagam-Baksh SM, Baksh FK, Swalsky PA, et al. Loss of heterozygosity in the MXI1 gene is a frequent occurrence in melanoma. Mod Pathol 2003;16:992-995.

74. Manni I, Tunici P, Cirenei N, et al. Mxi1 inhibits the proliferation of U87 glioma cells through down-regulation of cyclin $\mathrm{B} 1$ gene expression. $\mathrm{Br}$ J Cancer 2002;86:477-484.

75. Taj MM, Tawil RJ, Engstrom LD, et al. Mxi1, a Myc antagonist, suppresses proliferation of DU145 human prostate cells. Prostate 2001;47:194-204.

76. Huang X, Lin T, Gu J, et al. Combined TRAIL and Bax gene therapy prolonged survival in mice with ovarian cancer xenograft. Gene Ther 2002;9:1379-1386.
77. Magdolen U, Schroeck F, Creutzburg S, et al. Non-muscle alphaactinin-4 interacts with plasminogen activator inhibitor type-1 (PAl-1). Biol Chem 2004;385:801-808.

78. Ding Z, Liang J, Lu Y, et al. A retrovirus-based protein complementation assay screen reveals functional AKT1-binding partners. Proc Natl Acad Sci USA 2006;103:15014-15019.

79. Celli L, Ryckewaert JJ, Delachanal E, et al. Evidence of a functional role for interaction between ICAM-1 and nonmuscle alpha-actinins in leukocyte diapedesis. J Immunol 2006;177:4113-4121.

80. Gonzalez AM, Otey C, Edlund M, et al. Interactions of a hemidesmosome component and actinin family members. J Cell Sci 2001;114:4197-4206.

81. Kos CH, Le TC, Sinha $\mathrm{S}$, et al. Mice deficient in alpha-actinin-4 have severe glomerular disease. J Clin Invest 2003;111:1683-1690.

82. Nikolopoulos SN, Spengler BA, Kisselbach K, et al. The human nonmuscle alpha-actinin protein encoded by the ACTN4 gene suppresses tumorigenicity of human neuroblastoma cells. Oncogene 2000;19: 380-386.

83. Wang W, Wyckoff JB, Frohlich VC, et al. Single cell behavior in metastatic primary mammary tumors correlated with gene expression patterns revealed by molecular profiling. Cancer Res 2002;62: 6278-6288.

84. Wolf K, Wu Yl, Liu Y, et al. Multi-step pericellular proteolysis controls the transition from individual to collective cancer cell invasion. Nat Cell Biol 2007;9:893-904.

85. Wolf $\mathrm{K}$, Mazo I, Leung $\mathrm{H}$, et al. Compensation mechanism in tumor cell migration: mesenchymal-amoeboid transition after blocking of pericellular proteolysis. J Cell Biol 2003;160:267-277.

86. Wolf $\mathrm{K}$, Muller R, Borgmann S, et al. Amoeboid shape change and contact guidance: T-lymphocyte crawling through fibrillar collagen is independent of matrix remodeling by MMPs and other proteases. Blood 2003; 102:3262-3269. 